\title{
Comparing the Effects of Pure Problem-Based Learning and Hybrid Problem-Based Learning on Metacognitive Awareness in Nursing Students
}

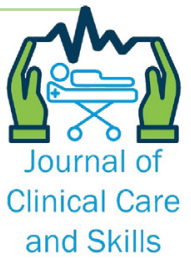

\section{ARTICLE INFO}

\section{Article Type}

Original Research

\section{Authors}

Zarida H. ${ }^{1} \mathrm{PhD}$

Zarifi A. ${ }^{2} P h D$,

Zoladl M. ${ }^{3} P h D$

Salari M.*4 $P h D$

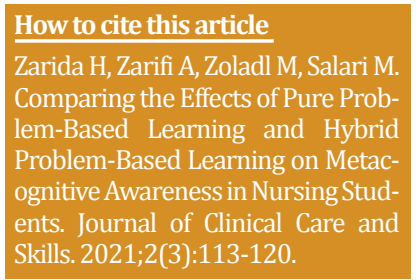

${ }^{1}$ Faculty of Medicine, University Putra Malaysia, Selangor, Malaysia

${ }^{2}$ English Language Department, Faculty of Humanities, Yasouj University, Yasuj, Iran

${ }^{3}$ Social Determinants of Health Research Center, Yasuj University of Medical Sciences, Yasuj, Iran

${ }^{4}$ Paediatric Nursing Department, School of Nursing, Yasuj University of Medical Sciences, Yasuj, Iran

\section{*Correspondence}

Address: School of Nursing, Next to Emam Sajad Hospital, Dr. Jalil Street, Yasuj, Iran. Postal code: 7591994799.

Phone: +98 (917) 7412035

Fax: +98 (74) 33224115

salarimo@yums.ac.ir

\section{Article History}

Received: January 11, 2021

Accepted: July 24, 2021

ePublished: September 11, 2021

\section{A B S T R A C T}

Aims Nursing students should be equipped with higher thinking strategies such as metacognitive and lifelong learning skills to make correct decisions in new situations. This study was conducted to compare the effect of different problem-based learning methods on metacognitive skills in nursing students.

Methods In this quasi-experimental study with pretest-posttest design, the subjects were undergraduate students enrolled in the Pediatric Nursing II course at Islamic Azad University in Iran. Ninety-five nursing students were selected by multistage cluster sampling method and divided into Pure Problem-Based Learning $(n=30)$, Hybrid Problem-Based Learning $(n=30)$, and Lecture-Based Method $(n=35)$. The intervention was conducted for eight weeks, during which the participants met once a week. Data were collected using the Metacognitive Awareness Inventory before and after each instructional method and analyzed in SPSS 17 software using the ANCOVA.

Findings A statistically significant difference was observed between the mean scores of overall metacognitive awareness for Pure Problem-Based Learning, Hybrid Problem-Based Learning, and Lecture-Based Method groups $(\mathrm{p}<0.01)$ and its sub-scales of knowledge of cognition and regulation of cognition $(\mathrm{p}<0.001)$ on the posttest. The mean score of metacognitive awareness for the Lecture-Based Method group was significantly lower than those of the Pure Problem-Based Learning and Hybrid Problem-Based Learning groups $(\mathrm{p}<0.05)$.

Conclusion Both Pure Problem-Based Learning and Hybrid Problem-Based Learning effectively enhance metacognitive skills in nursing students.

Keywords Problem-Based Learning; Lecture; Metacognitive Awareness; Nursing

\section{CIT A T I O N L I N KS}

[1] Assessing metacognitive ... [2] Metacognitive Aspects ... [3] The role of metacognitive knowledge in ... [4] Examining the effects of metacognitive ... [5] Iranian nurses' perceptions of theoretical ... [6] Problem-based learning in nurse education ... [7] What really motivates iranian nurses to be... [8] Problem based learning-bringing ... [9] Teaching nursing: Developing a student ... [10] Comparison between problem-based ... [11] The role of nurse educators' selfperception and ... [12] Constructivism theory analysis ... [13] Infusing learner-centered strategies into ... [14] Pure PBL, hybrid PBL and lecturing ... [15] Goals and strategies of a problem ... [16] Comparison of effectiveness between ... [17] Metacognitive skills for ... [18] Comparing hybrid problem ... [19] Problem-based learning: A strategic ... [20] Exploring consistency within ... [21] Problem-based learning and ... [22] Opinions of an Iranian nursing ... [23] Review of problembased learning trends ... [24] Use of a problem-based learning teaching ... [25] Addressing barriers to implementing problem ... [26] Nursing research: Methods and critical appraisal ... [27] Introduction to research ... [28] A power ... [29] Relationship between metacognition ... [30] Assessing cognitive and metacognitive ... [31] Meta-cognitive strategies and nursing ... [32] Improving students' learning ... [33] Educational research: Competencies ... [34] Effect of problem-based learning... [35] The influence of metacognitive s... [36] Astudy of the effectiveness ... [37] Application of problem based learning ... [38] Enhancing generic capabilities and ... [39] The effects of PBL(problem-based ... [40] Exploring the relationships between ... [41] Internet in the classroom: Effects ... [42] Effects of problem-based learning ... [43] Educational strategies to promote ... [44] What do we know about cognitive ... [45] Student and tutor satisfaction with ... [46] Impact of problem-based learning ... [47] Problem based learning (PBL) in Malaysian ... 


\section{Introduction}

Metacognition is defined by Schraw \& Dennison [1] as "the ability to reflect upon, understand, and control one's learning". It generally refers to the learner's knowledge about his/her cognitive processes and the ability to control these processes [2] actively. Metacognition has two main components, including knowledge about cognition and executive processes or regulation of cognition [3]. Metacognitive skills (planning, monitoring, evaluating) can be useful in problem-solving, improve academic achievement, content knowledge, and understanding [4]. Nursing students encounter many challenges in the current healthcare atmosphere [5]. They are likely to find themselves in new clinical situations for which they have no prior experience. In addition, traditional teaching methods may fail to enable them to cope with such situations [6] simply because information does not get internalized in traditional training situations. These methods often fail to develop students' creativity and critical thinking skills to make appropriate decisions in unexpected conditions $[7,8]$. Subsequently, the raised concern calls for an alternative approach with higher efficacy in teaching nursing [9].

Nursing education has conventionally focused on Lecture-Based Methods (LBM). Although the LBM is the best teaching method for immediate knowledge retention for nursing students [10], there has recently been a suggestion to move toward more learnercentered teaching strategies and pedagogies that can improve lifelong student learning [11]. Therefore, learner-centered teaching is considered a specific teaching method such as group work or ProblemBased Learning (PBL). Lerner-centered teaching is an umbrella framework rooted in constructivism that incorporates several various teaching strategies. These strategies make the constructivist learning environment more feasible and easier for students. Based on constructivism, students integrate new knowledge with prior knowledge to know the world [11]. Through constructivism, nursing students get engaged in discovering knowledge by working through the problems, issues and common scenarios in their profession. This process may help students to develop clinical reasoning skills [12]. In learnercentered teaching, students tend to construct understanding in an interactive, social context and learn to think critically and have cooperative learning [11, 13].

The Pure Problem-Based Learning (PPBL) strategy in this study refers to using the full PBL in a small-group setting without presenting a lecture in the teaching and learning of Pediatric Nursing topics [14]. It is commonly believed that PBL tutors may adopt different roles as a facilitator within the small group of PBL model to succeed in their responsibilities such as guiding students in the learning process, pushing students to think deeply, and modeling the types of questions that students require to ask themselves, forming a cognitive apprenticeship, modeling good strategies for learning and teaching as a skillful learner, supervising the discussion to select and execute appropriate strategies as needed [15]. In PBL, nursing students are highly challenged to solve clinical problems with their friends relevant to the nursing profession [16].

Applying PBL strategies can improve student's metacognitive awareness in problem-solving [17]. Moreover, the students will be able to control and lead their learning processes through different stages if they are active and aware of the learning process. Hybrid PBL (HPBL) pedagogy integrates the advantages of conventional teaching methods and novel teaching methods [18]. HPBL refers to the combination of PPBL with other learning strategies such as lectures [19]. The lecturer, through the minilecture, stimulates prior knowledge to be linked with new information. Assisting entering students to elucidate their preconceptions may ease a more complicated view of consistency in PBL-based programs and reduce early stress and anxiety [20].

Moreover, suggested a blended approach to produce both knowledge attainment and knowledge application [21]. It has been suggested that the integrated PBL and the other learning models were the best combinations of learning models that can be used to improve students' metacognitive skills [17]. So, the findings of this study would be significant because it takes a fresh look at different strategies from a new dimension. It is hoped that the findings of this study could shed new light on the benefits of the use of PPBL and HPBL in nursing.

There are some barriers to administering the PBL strategy in Iran: the large numbers of enrolled students and the lack of staff with sufficient skills and experience in PBL ${ }^{[22]}$. However, most nursing schools in Iran have not been able to complete curriculum change, chiefly because of inadequate evidence showing the advantages of the PBL methods in Iran. The characteristics of the education level of students and the environment in which they are exposed to the PBL method can significantly affect the heterogeneity of the effect of PBL on students' problem-solving skills [23]. A review of the related literature also indicates that little investigation has been conducted on the applications of PBL in the educational system of Iran [22, 24]. Faculty resistance, student concerns, and resource limitations have been identified as common barriers to PBL implementation [25]. Vahidi et al. reported that the majority of faculty indicated that the cost of implementation and maintenance of $\mathrm{PBL}$, too many students and a shortage of lecturers competent in PBL were among the barriers that needed to be considered [22]. Sayyah et al. believe that Iran has not yet developed an appropriate approach to substitute the conventional teaching methods [24]. In particular, no research has been carried out to 
compare the impact of PPBL and HPBL in the education of Pediatric Nursing. So, this study was conducted to compare the effect of problem-based learning methods with lecture-based methods on the metacognitive skills in nursing students.

\section{Methods}

This is a quasi-experimental study with a pretestposttest group design [26]. It took place in two branches of Islamic Azad University (IAU) in Gachsaran and Yasuj, Iran. It consisted of all the junior nursing students of IAU branches in Iran who attended the Pediatric Nursing II course. The population was junior nursing students of IAUs in Kohgiluyeh-BoyerAhmad province that had taken Pediatric Nursing II during the time the research was carried out in 2017. The sampling method was multistage cluster sampling [27]. Three out of the five intact classes in the target universities were chosen by the fish-bowl method. Subsequently, they were randomly assigned to the three groups of the study: $\mathrm{PPBL}=30, \mathrm{HPBL}=30$ and $\mathrm{LBM}$ (as control) $=35$. These classes were tested for homogeneity and their ability through comparing their scores on pediatric nursing. Accordingly, with power analysis of Compromise method, the power for effect size $(E S)=0.25$, which is close to medium, $\beta / \alpha$ ratio of $1: 1$ that is also the default in basic research, for a total sample size of 95 for three groups, was calculated to be more than 0.80 . This power is acceptable and proposed for general use [28]. Inclusion criteria were informed consent, same socioeconomic status, ethnic background and common abilities. Also, information about participation in PBL class or workshop was obtained for all of the groups. Exclusion criteria were missing two sessions, withdrawal or other conditions affecting the study.

The Metacognitive Awareness Inventory (MAI) was used to measure general students' metacognitive awareness as they were solving Pediatric Nursing problems. In this study, metacognitive awareness refers to students' awareness on two main metacognitive subscales, namely, knowledge of cognition and regulation of cognition, which indicates students' ability to reflect, know, understand, and control their learning by different strategies 52 -item MAI assesses. This instrument was adapted from Schraw and Dennison [1] and needed to be replied to on a five-point Likert scale. Mean scores ranged from 1.00 to 5.00 . This scoring was adopted based on some studies $[29,30]$. The students were required to show their ability to reflect, know, understand, and control their learning by different strategies while working on questions or problems by circling the proper scale where scale 1 indicated "seldom or never" occur, scale two indicated "only occasionally or rarely", scale 3 indicated "sometimes", scale 4 indicated "usually or often", and scale 5 indicated "almost always or always". There are two main metacognitive subscales, including knowledge of cognition and regulation of cognition during nursing problemsolving. In addition, knowledge of cognition has three minor subscales (sub-processes) that facilitate the reflective feature of metacognition: declarative knowledge, procedural knowledge, and conditional knowledge. Regulation of cognition includes five minor subscales (sub-processes or subcomponents) that facilitate the control aspect of learning, including planning, information management strategies, comprehension monitoring, debugging strategies, and evaluation. The score for each subscale ranged from 4 to 50, while the overall metacognitive awareness scale ranged from 52 to 260. Since the instrument was in English (source), the translation process was carried out as it was explained in the instrumentation subtopic. For content validation, the instrument was submitted to five nursing lecturers. CVR results (0.99) indicated that the questions were valid and in line with the Metacognitive Awareness and appropriate for Pediatric Nursing students. A pretest metacognitive awareness was administered at the beginning of the interventions while the students were solving the prior performance test problems, and the second time it was administered when students were solving the posttest problems. The reliability of this instrument was established once before it was used in the actual study. Forty nursing juniors that were not involved in the actual study were asked to do the survey. The results showed that the instruments were reliable $(r=0.74)$ and valid [31]. The students' comments were considered in improving the instruments. The overall reliability coefficient for the questionnaire was $r=0.90$. The reliability was 0.70 and 0.85 for knowledge of cognition and regulation of cognition subscales, respectively. The nursing juniors were also interviewed on the clarity of the survey questions and their understanding of the survey questions.

The study was registered in the Research Ethics Committee of Yasuj University of Medical Sciences. Students' informed and written consent was obtained before the intervention and after a complete explanation about the purpose of the study. Other ethical considerations were the confidentiality of the information collected, voluntary participation in the study, and the possibility of withdrawal at any study stage. The total duration of the intervention was eight weeks.

The PPBL group underwent learning using the pure problem-based learning approach with guided questions and a tutor; the HPBL group was exposed to a problem-based learning approach with minimal lecturing, guided questions and a tutor; and the LBM group experienced learning using conventional instruction utilizing full lecture.

The following steps were taken to prepare the materials and teach and learn the topics in the PPBL strategy. 
Comparing the Effects of Pure Problem-Based Learning ...

i. Three elements constituted the basis for developing a good trigger or problem, including learning context, students, curriculum, and standards.

ii. To define what the students knew and needed to know, they were required to meet the problem by planning key questions, defining the problem statement, gathering and sharing information, generating possible solutions, choosing the most viable solution, problem assessment, and debriefing the problem experience.

iii. Students' thinking and inquiry had to be facilitated or coached by the facilitator with minimal guidance as the students took an active role and were responsible for their learning to solve the problems.

iv. The students were asked to summarize the lesson learned with correction feedback from the facilitator. Summarization as a technique was an effective learning approach for students who were already skilled at summarizing, and it could help increase students' learning, understanding, and retention of materials [32].

The following were implemented in preparing the materials and teaching and learning the topics in the HPBL strategy.

i. Three elements constituted the basis for developing a good trigger or problem: learning context, students, curriculum, and standards.

ii. By familiarizing the learning baseline or context, the students were better prepared to manage the HPBL strategy problem. The lecturer, through the minilecture, stimulated prior knowledge to be linked with new information. Assisting entering students to elucidate their preconceptions could ease a more complicated view of consistency in PBLbased programs and reduce early stress and anxiety [20]. Then the students met the problem, defined what they knew and needed to know by planning key questions, defining problem statements, gathering and sharing information, generating possible solutions, choosing the most viable solution, problem assessment, and debriefing the problem experience.

iii. The lecturer had to facilitate or coach students' thinking and inquiry with guidance as students were taking an active role and were responsible for their learning to solve the problems.

iv. After summarization by the students, the lecturer gave a feedback session to summarize the lesson content and provided a conclusion part to provide the students with accurate information.

The following were the activities performed by the lecturer in the LBM classroom:

i. The lecturer clarified the concepts of organ dysfunction in the Pediatric Nursing II course either through a whiteboard or PowerPoint.

ii. The lecturer described how to solve Pediatric Nursing problems in relevance with the concepts.

iii. The students answered the given Pediatric Nursing problems (questions based on a scenario) individually.

iv. The lecturer ran the question-answer session.

v. At the end of the session, the lecturer concluded the lesson, and the students summarized the learned materials.

Then, the teaching materials were implemented with the three intact classes of junior nursing undergraduates at the target University branches. Four main topics were taught during eight weeks. This means that each main topic was covered in two weeks. Every other week, the students attended one two-hour session and two two-hour sessions. In each session, the students in a PBL tutorial were assigned to three roles: chair or leader, scribe and group members, and these roles were rotated during the sessions. In the PPBL and HPBL, the leader managed the discussion, and the scriber noted the group activities and focused on summarizing what the group members discussed. The students also had independent study and discussion between the sessions. Next, to make decisions about the worth or value of the instructions, summative evaluations were conducted during the posttest and delayed posttest to evaluate the students' retention. These tests were administered to determine the effectiveness of the PBL teaching methods and to see whether the students achieved the materials based on the study's objectives. The treatment was carried out over a period of two months (8 weeks). Metacognitive awareness questionnaire was given to the students before and after the intervention.

SPSS 17 software was used to analyze the collected data. After conducting exploratory data analysis and running Shapiro-Wilk and Leven's test to assess the normality and homogeneity of variances of the data, ANCOVA and Tukey's post hoc test was employed for data analysis. The alpha level was set at 0.05 because this level is acceptable for most educational research [33].

\section{Findings}

A total of 95 students in three groups were studied, and all of them participated in the study. All of the students were nursing majors and female. A majority $(84.21 \%)$ of the students were aged $21-23$, while the rest (15.79\%) were above 23 . 
The total mean of Pediatric Nursing scores was 13.57. The mean Pediatric Nursing I scores for the PPBL, HPBL, and LBM groups were 13.48 $\pm 1.76,13.79 \pm 1.88$, and 13.45 \pm 1.66 , respectively. There was no significant difference between the mean of Pediatric Nursing I scores for the PPBL group, HPBL group and LBM group $\left(\mathrm{F}_{(2,92)}=0.34, \mathrm{p}>0.05\right)$.

The correlation matrix showed a medium, positive correlation $(r=0.29, \mathrm{p}<0.005)$ between the posttest metacognitive awareness and its related covariate. Also, the posttest knowledge of cognition with its covariate had a medium, positive correlation $(\mathrm{r}=0.22$, $\mathrm{p}<0.05)$. The correlation between the posttest regulation of cognition and its covariate was large and positive $(r=0.55, \mathrm{p}<0.005)$.

Based on the results, the overall mean of metacognitive awareness levels of the PPBL group was $3.91 \pm 0.40$ while the mean metacognitive awareness of the HPBL group was $3.81 \pm 0.36$ and the mean of metacognitive awareness of the LBM strategy group was $3.43 \pm 0.38$. The ANCOVA test showed that the differences between the means of metacognitive awareness of the three groups were significant $(p<0.001)$. Based on the post-hoc test, the mean of metacognitive awareness of the LBM group was significantly lower than the metacognitive awareness of the PPBL and HPBL groups $(\mathrm{p}<0.05)$. In addition, the Pairwise comparison indicated that there was a significant difference in the mean difference score of overall metacognitive awareness attained by the LBM group and the mean difference score of the PPBL and HPBL groups $(\mathrm{p}<0.05)$. However, there was no significant difference in the PPBL and HPBL groups ( $\mathrm{p}>0.05)$.

The ANCOVA test showed that the differences between the three groups' means of knowledge of cognition subscale were significant $(p<0.05)$. The post hoc results indicated that the LBM group's mean cognition level was significantly lower than the knowledge of cognition of the PPBL and HPBL groups. In addition, a Pairwise comparison indicated that there was a significant difference in the mean difference score of knowledge of cognition attained by the LBM group and the mean difference score of the PPBL and HPBL groups $(\mathrm{p}<0.05)$. However, there was no significant difference in the PPBL and HPBL groups ( $\mathrm{p}>0.05)$.

Analysis of mean differences in regulation of cognition subscale between the three groups was significant $(\mathrm{p}<0.05)$. In addition, the mean regulation of cognition level of the LBM group was significantly lower than those of the PPBL and HPBL groups. Pairwise comparison indicated a significant difference in the mean difference score of regulation of cognition attained by the LBM group and the mean difference scores of the PPBL and HPBL groups $(p<0.05)$. However, there was no significant difference in the PPBL and HPBL groups ( $p>0.05)$.

\section{Discussion}

The main purpose of this intervention was to investigate the effects of the PPBL, HPBL and LBM strategies on Metacognitive Awareness in learning the Pediatric Nursing course. The findings can shed new light on the benefits of using PPBL and HPBL with one floating tutor in nursing. This study can also be particularly valuable to nursing lecturers as they struggle to identify appropriate strategies for offering appropriate tutoring in a large classroom of PBL. The results showed that the PBL strategy groups had superior overall metacognitive skills and the relevant subscales than the LBM strategy group on the posttest. The implication is that the PBL strategies could be more effective than the LBM strategy to develop and maintain students' skills [34] and problem-solving [21].

Metacognitive skills such as self-regulation skills are essential for nursing students [35]. This is in line with Shetty and Bachtiar, who found that PBL effectively improved students' metacognitive awareness and metacognitive skills. More specifically, they proved that PBL could help students extend their knowledge and regulation of cognition [36, 37]. Despite LBM, interactive learning activities such as PBL produced a learning environment that enabled students to plan, organize, implement and evaluate their learning strategies. This learning process included the crucial elements of cognition regulation [1]. Chan et al.'s study supported the statement that active learning strategy could help develop the metacognitive awareness of nursing students [38].

Inconsistent with the available literature on metacognitive awareness [17], the results of this study indicated that the PBL strategy groups had higher means for the overall level of metacognitive awareness compared to that of the LBM group. The present study suggest that there was sufficient evidence to conclude that the use of PBL strategies can boost students' metacognitive awareness level during solving problems in Pediatric Nursing.

Contrary to the present study's findings, in a study to determine the effect of PBL on the critical thinking and problem-solving process, Choi concluded that PBL did not improve the participants' critical thinking. The relationship between critical thinking and problem solving was not supported [39].

The differences were significant because the students in both PPBL and HPBL strategy groups were asked to perform the tasks and process the problems in pairs and small study groups. Also, they were encouraged to discuss the problems among themselves for better learning. Thus interactions among the group members might have benefited the students in PBL strategy groups in demonstrating a higher level of metacognitive awareness.

The findings of this study are consistent with earlier studies in providing empirical evidence for the 
Comparing the Effects of Pure Problem-Based Learning ... development of metacognitive awareness behavior and its impact on achievement. For example, [30] noted a positive, moderate and significant relationship between problem-solving performance and achievement with metacognitive strategies. Martyn et al. [40] also revealed a significant relationship between PBL and critical thinking as a metacognitive skill. When the students are free to identify and precede their learning in a complex environment, it assists them in developing their metacognitive skills [9].

Similar to the study carried out by Silitonga \& Harahap, the present study revealed that PBL could successfully improve student learning outcomes, encourage teamwork skills, critical thinking and problem-solving skills [16]. However, PBL is better at motivating and increasing awareness about lectures to be used more effectively in lectures. There is a definite positive link between metacognitive awareness and learner accomplishments [41]. The core activity in PBL is small group learning. The PBL employs small groups centered on solving wellintegrated learning problems instead of large groups as in conventional instruction [42]. In small groups, the tutor acts like a metacognitive guide; without giving the answers, the facilitator is there to help students raise questions. It seems that metacognitive awareness may play a greater role in complex tasks [9]. Silitonga et al. reported that students are greatly challenged to solve clinical problems related to the nursing profession with their friends [16].

In PBL strategies, the facilitator provides students with clues during class discussions and leads them to think deeper, discuss more, reflect further and conduct more research to achieve higher performance. Based on the present study results, it can be concluded that the positive impact of PBL strategies on metacognitive awareness can lead the students to accomplish higher achievement [43]. According to Dolmans \& Schemit, in a PBL session, group discussion stimulates the previously activated knowledge and brings it to mind. It also urges information construction, causal reasoning, collaborative learning construction, and cognitive conflicts that lead to conceptual change. Nursing students involved in clinical experience usually investigate the health care setting situations of the clients by using the same PBL format as that used in the classroom [44]. Creedy et al. claim that students are usually encouraged in the PBL approach to be active creators rather than passive knowledge receptors. Hence, nursing students have the opportunity to develop, apply, and evaluate their understanding related to the concepts being studied for simulated and actual clinical situations [6].

There are, however, some barriers to administer the PBL strategy in Iran, namely, the large numbers of enrolled students and the lack of staff with sufficient skills and experience in PBL [22]. In the study of Sattarova et al., there were other barriers such as student engagement and motivation problems. In addition, students are not sufficiently familiar with and knowledgeable about PBL. Moreover, there was an issue with a few tutors who were not confident with PBL and who claimed that it did not enable them to be sufficiently effective and professional [45]. There were no significant differences between the HPBL and PPBL groups regarding metacognitive awareness in the present study. In this regard, some researchers suggest the suitability of a Hybrid PBL approach and a gradual PBL foreword throughout the academic years at times when PBL is new to students because hybrid course or a blend of PBL and lecture can develop students' ability to solve problems in a large classroom setting [46, 47]. According to Surati et al., students' metacognitive skills varied when exposed to different learning models. The students' metacognitive skills were also affected by their academic abilities. Finally, it was suggested that the integrated PBL could improve students' metacognitive skills [17].

This study had some limitations. Four out of nine main topics of organ dysfunction with high prevalence in the Pediatric Nursing syllabus were used in this study, and the intervention was done over eight weeks of teaching sessions. Also, since the researcher could not change the regular program of the universities to randomize the assignment of the subjects to different groups, the study included only intact classes of third-year nursing students in a bachelorette program.

\section{Conclusion}

Both Pure Problem-Based Learning and Hybrid Problem-Based Learning effectively enhance metacognitive skills in nursing students.

Acknowledgments: The authors wish to thank all the accessible nursing students for their time and participation in this study. Thanks are also due to Gachsaran and Yasuj Islamic Azad Universities' chancellors for permitting the researchers to conduct the study.

Ethical Permissions: The Deputy Chancellors of Yasuj University of Medical Sciences granted ethical approval for this study with reference number 5/3473.

Conflicts of Interests: None declared by authors.

Authors' Contribution: Zarida H. (First Author), Introduction Writer/Assistant Researcher/Discussion Writer (20\%); Zarifi A. (Second Author), Introduction Writer/Methodologist/Discussion Writer (20\%); Zoladl M. (Third Author), Methodologist/Introduction Writer/Discussion Writer (20\%); Salari M. (Fourth Author), Introduction Writer/Original Researcher/Statistical Analyst/Discussion Writer (40\%)

Funding/Support: None declared by authors.

\section{References}

1- Schraw G, Dennison RS. Assessing metacognitive awareness. Contemp Educ Psychol. 1994;19(4):460-75.

2- Flavell JH. Metacognitive Aspects of Problem Solving. In: Resnick LB. The nature of intelligence. Hillsdale: Lawrence Erlbaum; 1976. 
3- Pintrich PR. The role of metacognitive knowledge in learning, teaching, and assessing. Theory Into Pract. 2002;41(4):219-25.

4- An YJ, Cao L. Examining the effects of metacognitive scaffolding on students' design problem solving and metacognitive skills in an online environment. J Online Learn Teach. 2014;10(4):552-68.

5- Cheraghi MA, Salsali M, Ahmadi F. Iranian nurses' perceptions of theoretical knowledge transfer into clinical practice: A grounded theory approach. Nurs Health Sci. 2007;9(3):212-20.

6- Creedy D, Horsfall J, Hand B. Problem-based learning in nurse education: An Australian view. J Adv Nurs. 1992;17(6):727-33.

7- Shahsavari Isfahani S, Hosseini MA, Fallahi Khoshknab M, Peyrovi H, Khanke HR. What really motivates iranian nurses to be creative in clinical settings: A qualitative study. Glob J Health Sci. 2015;7(5):132-42.

8- Vittrup AC, Davey A. Problem based learning-bringing everything together-a strategy for graduate nurse programs. Nurse Educ Pract. 2010;10(2):88-95.

9- Young LE, Patterson BL. Teaching nursing: Developing a student-centered learning environment. Philadelphia: Lippincott Williams \& Wilkins; 2007.

10- Solomon Y. Comparison between problem-based learning and lecture-based learning: Effect on nursing students' immediate knowledge retention. Adv Med Educ Pract. 2020;11:947-52.

11- Ellis DM. The role of nurse educators' self-perception and beliefs in the use of learner-centered teaching in the classroom. Nurse Educ Pract. 2016;16(1):66-70.

12- Brandon AF, All AC. Constructivism theory analysis and application to curricula. Nurs Educ Perspect. 2010;31(2):89-92.

13- Schroeder SJ. Infusing learner-centered strategies into the classroom. Occup Ther Health Care. 2012;26(4):21823.

14- Salari M, Roozbehi A, Zarifi A, Tarmizi RA. Pure PBL, hybrid PBL and lecturing: Which one is more effective in developing cognitive skills of undergraduate students in pediatric nursing course. BMC Med Educ. 2018;18(1):195. 15- Hmelo-Silver CE, Barrows HS. Goals and strategies of a problem-based learning facilitator. Interdiscip J Problem Based Learn. 2006;1(1):21-39.

16- Silitonga LL, Harahap RF. Comparison of effectiveness between PBL and LBL in improving student learning outcomes. Int J Nurs Educ. 2020;12(4):296-302.

17- Surati DS, Bachtiar S, Rijal M, Mastuti AG. Metacognitive skills for the integrated problem based numbered head together learning. J Southwest Jiaotong Univ. 2021;56(2):605-17.

18- Liu CX, Ouyang WW, Wang XW, Chen D, Jiang ZL. Comparing hybrid problem-based and lecture learning (PBL+LBL) with LBL pedagogy on clinical curriculum learning for medical students in China: A meta-analysis of randomized controlled trials. Medicine. 2020;99(16):19687.

19- Gwee MCE. Problem-based learning: A strategic learning system design for the education of healthcare professionals in the 21st century. Kaohsiung J Med Sci. 2009;25(5):231-9.

20- Landeen J, Jewiss T, Vajoczki S, Vine M. Exploring consistency within a problem-based learning context: Perceptions of students and faculty. Nurse Educ Pract. 2013;13(4):277-82.
Zarida H. et al.

21- Carriger MS. Problem-based learning and management development-empirical and theoretical considerations. International J Manag Educ. 2015;13(3):249-59.

22- Vahidi RG, Azamian A, Valizadeh S. Opinions of an Iranian nursing faculty on barriers to implementing problem-based learning. East Mediterr Health J. 2007;13(1):193-6.

23- Suparman S, Juandi D, Tamur M. Review of problembased learning trends in 2010-2020: A meta-analysis study of the effect of problem-based learning in enhancing mathematical problem-solving skills of Indonesian students. J Phys Conf Ser. 2021;1722(1):012103.

24-Sayyah M, Shirbandi K, Saki-Malehi A, Rahim F. Use of a problem-based learning teaching model for undergraduate medical and nursing education: A systematic review and meta-analysis. Adv Med Educ Pract. 2017;8:691-700.

25- Henderson KJ, Coppens ER, Burns S. Addressing barriers to implementing problem-based learning. AANA J. 2021;89(2):117-24.

26- LoBiondo-Wood G, Haber J. Nursing research: Methods and critical appraisal for ecidence-based practice. Meryland Height: Mosby Elsevier; 2014.

27- Ary D, Jacobs LC, Razavieh A, Sorensen C. Introduction to research in education. Belmont: Thomson Wadsworth; 2006.

28- Cohen J. A power primer. Psychol Bull. 1992;112(1):155-9.

29- Gul F, Shehzad S. Relationship between metacognition, goal orientation and academic achievement. Proced Soc Behav Sci. 2012;47:1864-8.

30- Bayat S, Tarmizi RA. Assessing cognitive and metacognitive strategies during algebra problem solving among university students. Proced Soc Behav Sci. 2010;8:403-10.

31- Salari M, Hamzah R, Hamzeh R, Hambali Z. Metacognitive strategies and nursing students' achievement. J Educ Vocat Res. 2013;4(6):169-73.

32- Dunlosky J, Rawson KA, Marsh EJ, Nathan MJ, Willingham DT. Improving students' learning with effective learning techniques: Promising directions from cognitive and educational psychology. Psychol Sci Public Interest. 2013;14(1):4-58.

33- Gay LR, Mills GE, Airasian P. Educational research: Competencies for analysis and applications. Columbus: Merrill Greenwood; 2006.

34- Salari M, Zarifi A, Tarmizi RA. Effect of problem-based learning on communication skills of undergraduate nursing students. J Clin Care Skills. 2021;2(1):21-7. [Persian]

35- Howard BC, McGee S, Shia R, Hong NS. The influence of metacognitive self-regulation and ability levels on problem solving [Report]. Washington: ERIC; 2001, Report NO:ED470974.

36- Shetty GS. A study of the effectiveness of problem based learning in developing metacognitive skills in student teachers [dissertation]. Mumbai: SNDT Womens University; 2008.

37- Bachtiar S. Application of problem based learning model to enhance critical thinking ability, metacognitive awareness and cognitive learning outcomes in class XI SMAN 1 Binamu [dissertation]. Makassar: State University of Makassar; 2013.

38- Chan CWH, Tang FWK, Chow KM, Wong CL. Enhancing generic capabilities and metacognitive awareness of firstyear nursing students using active learning strategy. BMC Nurs. 2021;20(1):81. 
Comparing the Effects of Pure Problem-Based Learning ... 39- Choi HJ. The effects of PBL(problem-based learning) on the metacognition, critical thinking, and problem solving process of nursing students. Taehan Kanho Hakhoe Chi. 2004;34(5):712-21. [Korean]

40- Martyn J, Terwijn R, Kek MYCA, Huijser H. Exploring the relationships between teaching, approaches to learning and critical thinking in a problem-based learning foundation nursing course. Nurse Educ Today. 2014;34(5):829-35.

41- Kramarski B, Feldman Y. Internet in the classroom: Effects on reading comprehension, motivation and metacognitive awareness. Educ Media Int. 2000;37(3):14955.

42- Choi E, Lindquist R, Song Y. Effects of problem-based learning vs. traditional lecture on Korean nursing students' critical thinking, problem-solving, and self-directed learning. Nurse Educ Today. 2014;34(1):52-6.
43- Bowen JL. Educational strategies to promote clinical diagnostic reasoning. N Engl J Med. 2006;355(21):2217-25. 44- Dolmans DHJM, Schemit HG. What do we know about cognitive and motivational effects os small group tutorials in problem based learning. Adv Health Sci Educ Theory Pract. 2006;11(4):321-36.

45- Sattarova U, Groot W, Arsenijevic J. Student and tutor satisfaction with problem-based learning in Azerbaijan. Educ Sci. 2021;11(6):288.

46- Klegeris A, Hurren H. Impact of problem-based learning in a large classroom setting: Student perception and problem-solving skills. Adv Physiol Educ. 2011;35(4):40815.

47- Borhan MT. Problem based learning (PBL) in Malaysian higher education: A review of research on students' experience and issues of implementations. ASEAN J Eng Educ. 2012;1(1):48-53. 